\title{
Modified Tannin Extracted from Black Wattle Tree as Environmental-Friendly Antifouling Pigment
}

\author{
Rafael S. Peres, ${ }^{1}$ Elaine Armelin, ${ }^{2,3}$ Carlos Alemán ${ }^{2,3}$ and Carlos A. Ferreira, ${ }^{1}$ \\ ${ }^{1}$ LAPOL/PPGE3M, Universidade Federal do Rio Grande do Sul, Av. Bento Gonçalves 9500, 91501-970, \\ Porto Alegre, Brazil \\ ${ }^{2}$ Departament d'Enginyeria Química, ETSEIB, Universitat Politècnica de Catalunya, Av. Diagonal 647, \\ 08028 Barcelona, Spain \\ ${ }^{3}$ Centre for Research in Nano-Engineering, Universitat Politècnica de Catalunya, Campus Sud, Edifici \\ C', C/Pasqual i Vila s/n, Barcelona E-08028, Spain.
}

\begin{abstract}
The use of modified black wattle tannin as antifouling pigment is reported in this work. Mixture of tannin adsorbed in activated carbon (soluble fraction of tannin) and low soluble fraction of tannin was used as antifouling pigment. The soluble rosin resin was used as paint matrix. ${ }^{13} \mathrm{C}$ NMR analysis confirm the modification of black wattle tannin through the cleavage of tannin interflavonoid bonds. FTIR spectra indicates the presence of tannin in the formulated antifouling coating even after 7 months of its exposure in marine environment. Water contact angle analysis shows the hydrophilic characteristic of tannin antifouling coating surface. Immersion tests at Badalona port in Mediterranean Sea shows the high antifouling efficiency of TAN coating, comparable to the commercial paint, until 7 months. The use of a natural black wattle tannin, without its complexation with metals, can eliminate the release of metals and other toxic biocides to the marine environment.
\end{abstract}

Keywords: Antifouling; Coatings; Tannin; Black Wattle; Environment-friendly; 


\section{Introduction}

Hulls, submersed vessels and structures are subject to the attachment of organisms on its surface. ${ }^{1}$ The accumulation of these organisms form a layer called marine biofouling, its thickness depending on the organism species, water environment and season., ${ }^{2,3}$ Barnacles, mussels, hydroids, molluscs, tubeworms and algae are the most common types of fouling organisms found in submersed structures and hulls. ${ }^{3}$ The presence of fouling attached to ship hulls increases the friction with water, rising the fuel consumption. ${ }^{3,4}$ Maintenance costs of hulls, turbines, heat exchangers and ducts of hydroelectric plants are also affected by fouling. ${ }^{5}$ Economically, the fouling causes serious financial loss to the industry and, therefore, control of this organism accumulation is mandatory. ${ }^{3}$

The most common method to protect immersed structures against fouling is the use of antifouling paints. ${ }^{6}$ In the past, several toxicants as arsenic and mercury oxide were added to resin matrixes, but in the 1950s the concern about health problems led to eliminate these products from the market. $^{7}$ The development of tributyltin (TBT) compound introduced in the antifouling market one of the most effective product ever made. ${ }^{8}$ Its high durability and efficiency resulted in considerable savings in maintenance costs of ship hulls. ${ }^{8}$ However, TBT was considered one of the most toxic biocides purposely released in the marine environment. ${ }^{8}$ Studies showed that TBT impair the embryogenesis and larval development of oysters having harmful effect, even at very low concentration (i.e. $\left.0.05 \mu \mathrm{g} \mathrm{L} \mathrm{L}^{-1}\right) \cdot{ }^{9,10}$ As a consequence, the use of organotins compounds (including TBT) on ships was forbidden by the International Maritime Organization (IMO). ${ }^{11}$

New alternatives to TBT were development and, currently, the most usual antifouling pigment is copper oxide. ${ }^{3}$ The copper was used since 1800 s, even though its 
utilization depends of the local legislation. ${ }^{3}$ However, copper is categorized as considered toxic for the marine environment when its concentration exceed some threshold limits. ${ }^{12}$ Others biocides, such as Diuron ${ }^{\circledR}$ and Irgarol $^{\circledR} 1051$, are used together (co-biocides) with copper pigment, even though they are harmful to phytoplankton organisms. ${ }^{13}$ The use of Diuron ${ }^{\circledR}$ is not allowed in the United Kingdom while Irgarol ${ }^{\circledR}$ 1051 is limited to small watercrafts. ${ }^{14}$ Metallic pyrithiones are also used as co-biocides. However, these compounds show high toxicity for some fish species (skeletal deformities were reported). ${ }^{15}$ Inside this scenario, research on environmental-friendly antifouling agents and coatings has received increasing attention.

Many natural compounds with antifouling properties were found in natural products, as reported by several authors. Etoh et al. ${ }^{16}$ isolated shogaols from roots of ginger that are three times more active than copper sulphate. The behaviour of trans-8shogaol is similar to that of tributyltin fluoride (TBTF) against adhesion of blue mussel. ${ }^{16}$ Etoh et al. ${ }^{17}$ also isolated neocurdione, isoprocurcumenol and 9-oxoneoprocurcumenol from Curcuma aromatic and Curcuma zedoaria, using them as antifouling agents against blue mussel. Watts ${ }^{18}$ reported the application of natural or synthetic capsaicin mixed with epoxy resin as antifouling agent. In fact, large-scale extraction of natural antifouling agents has become one of the main challenges in the development of ecologic antifouling paint formulations. ${ }^{19}$

Tannins are natural polyphenolic compounds associated with defence mechanism of plants. ${ }^{20}$ Large amounts of these compounds are typically found in bark, roots, wood and seeds of many trees. ${ }^{21,22}$ Tannins can be classified as condensed, hydrolysable and phlorotannins. ${ }^{23,24}$ Condensed tannins are formed by flavonoid units that release anthocyanidins in a controlled medium (i.e. alcohol solutions at high temperatures in presence of strong acids). ${ }^{23,25}$ Hydrolysable tannins are constituted by 
gallic acid and its derivatives, which can be esterified to polyols. ${ }^{26}$ Phlorotannins, which are found only in brown algae, are based on phloroglucinol. ${ }^{23,26}$ Tannins are applied in several fields, as for example surface preparation, ${ }^{27,28}$ corrosion, ${ }^{29-31}$ leather tannin industry $^{32}$ and adhesives. ${ }^{33}$

The antifouling properties of Sargassum phlorotannin were reported by Sieburth and Conover in $1965 .{ }^{34}$ Chet et al. ${ }^{35}$ evidenced that tannic acid acts as repellent of bacteria in immersed surfaces. The presence of bacteria in immersed surfaces is frequently associated to the attachment of fouling species. ${ }^{2,35}$ Lau and Qian ${ }^{36}$ studied the inhibitory effect of phlorotannins, phloroglucinol and tannic acid on the settlement of Barnacle (Balanus amphitrite amphitrite). The toxicity and inhibitory effect on the fouling settlement were tested for three larval stages, results depending on the fouling specie and chemical characteristics of the phenolic compounds. ${ }^{36}$ Some works reported the utilization of tannates as antifouling agents in coating formulations. ${ }^{6,37-43}$ Tannates are organometallic compounds derived from the reaction of tannins and metallic salts. ${ }^{44}$ Pérez at al. ${ }^{6,37}$ used the copper and aluminium tannates (from quebracho tannin) in the formulation of antifouling coatings. Bellotti et al. ${ }^{39-43}$ reported the utilization of zinc tannates obtained by reaction of tara and quebracho tannins with zinc nitrate. Stupak et $a l .{ }^{38}$ found that aluminium tannate (from quebracho, chestnut and mimosa tannins) has a narcotic effect on nauplii of Balanus amphitrite. Due to the high solubility of tannin in water, the syntheses of tannates with zinc, copper and aluminium are necessary do decrease the tannin solubility. ${ }^{39}$

The aim of this study is to investigate the use of a modified black wattle tannin (extract from Acacia mearnsii) as an environmental-friendly antifouling agent. The tannin has been modified in an alcoholic medium at high temperatures with the presence of chloride acid, following by adsorption of its soluble fraction in activated carbon. The 
adsorbed and low soluble fractions of black wattle tannin have been used as pigment. The antifouling coatings have been formulated with a natural soluble matrix (rosin). This method avoids the utilization of metals enabling the utilization of pure tannin, which contribute to the formulation of an environmental-friendly coating.

\section{Experimental Procedure}

\subsection{Materials}

Black wattle tannin (TANAC, Brazil), $\mathrm{HCl}$ (Synth, Brazil), absolute ethanol (Synth, Brazil) and activated carbon powder (Delaware, Brazil) were used in the preparation of antifouling pigment. Coatings were prepared using rosin grade WW (RB Sul, Brazil) as matrix and methyl ethyl ketone (MBN chemicals, Brazil) as solvent. The commercial antifouling coating Micron ${ }^{\circledR}$ Premium (Akzo Nobel, USA) was used as a control of the antifouling activity and the two-component epoxy primer Intergard 269 (Akzo Nobel, USA) was used as an anticorrosive primer and blank.

\subsection{Black wattle tannin modification and antifouling pigment preparation}

The modification of black wattle tannin was based on Swain and Hills work, ${ }^{45}$ even though with some variations. Firstly, $10 \mathrm{~g}$ of black wattle tannin was dissolved in $180 \mathrm{~mL}$ of absolute ethanol followed by addition of $10 \mathrm{~mL}$ of deionized water. The mixture was stirred magnetically until homogenization and $10 \mathrm{~mL}$ of concentrated hydrochloric acid was added carefully (drop-by-drop) in the mixture. After complete addition of the hydrochloric acid, the mixture was heated at $70^{\circ} \mathrm{C}$ until almost complete evaporation of alcoholic solution. Then, $200 \mathrm{~mL}$ of deionised water was added followed by vigorous stirring. After dissolution of the soluble fraction of black wattle tannin, $20 \mathrm{~g}$ of activated carbon powder was added and stirred for 1 hour. At the end of adsorption 
process, the pigment formed by soluble tannin fraction (adsorbed in activated carbon) and low soluble tannin fraction, was filtered in a Büchner funnel and dried for 24 hours at $60^{\circ} \mathrm{C}$.

Chemical structure modification of tannin after hydrolysis was verified by ${ }^{13} \mathrm{C}$ NMR and FTIR spectroscopies. ${ }^{13} \mathrm{C}$ NMR spectra were performed using a $300 \mathrm{MHz}$ Bruker AMX300 spectrometer operating at $75.5 \mathrm{MHz}$. The soluble fraction of black wattle tannin was diluted in DMSO- $d_{6}$ and the internal standard was tetramethylsilane. FTIR spectra were recorded using a FTIR 4100 Jasco spectrophotometer coupled with an attenuated total reflection accessory (Specac model MKII Golden Gate Heated Single Reflection Diamond ATR). Spectra were obtained after 32 scans at a resolution of 4 $\mathrm{cm}^{-1}$, in a spectral range of $600-4000 \mathrm{~cm}^{-1}$, in transmittance mode.

\subsection{Antifouling coating preparation}

Initially, $48 \mathrm{~g}$ of rosin flakes were dissolved in $50 \mathrm{~mL}$ of MEK. Then, the dissolved rosin was added in the jacketed reactor of a Dispermat N1 (VMA-Getzmann GMBH of Reichshof, Germany) disperser equipped with a Cowles disk. The rosin was dispersed by 10 minutes before addition of antifouling pigment (tannin adsorbed in activated carbon and low soluble tannin fraction). Next, $27 \mathrm{~g}$ of antifouling pigment and $50 \mathrm{~mL}$ of MEK was added slowly. The mixture (coating) was dispersed at $4000 \mathrm{rpm}$ for 2 hours. After dispersion process, the pigments of the antifouling coating were milled on a Dispermat SL-12 ball mill (VMA- Getzmann GMBH of Reichshof, Germany). More MEK was added in the mill process according to the system demand (viscosity adjust). The mill process stop when the pigments reached a size between $25-15 \mu \mathrm{m}$ (6 and 7 Hegman). 


\subsection{Samples preparation and characterization}

Commercial, antifouling and blank coatings were applied over AISI 1010 steel panels with size of $25 \times 20 \times 1 \mathrm{~cm}$. Before the coatings application, surfaces of steel panels were treated as follow: degreasing with acetone; polishing with sandpaper (grain size \#150); cleaning with water; and degreasing with acetone again. After their preparation, steel panels were drilled in each corner for subsequent fixation. Next, the sides of each panel were painted with anticorrosive primer to protect the steel from marine environment. Commercial (COM) and tannin-based antifouling (TAN) coatings were applied only in one side of the panel. All coatings were applied by brush and dried at room temperature for 48 hours before immersion tests. The dry film thickness was measured with a Byko-7500 test unit (BYK Gardner, Germany). Measurements were repeated twelve times in different areas of the sample. The average thickness with the corresponding standard deviation obtained for COM, blank and TAN coatings is $214 \pm$ $13 \mu \mathrm{m}, 39 \pm 4 \mu \mathrm{m}$ and $254 \pm 14 \mu \mathrm{m}$, respectively.

\subsection{Measurements (}

Scanning electron microscopy (SEM) analyses were carried out using a focused ion beam Zeiss Neon 40 microscope operating at $5 \mathrm{kV}$. Optical microscopy images were obtained using a Dino-lite USB digital microscopy. FTIR analyses were performed using a Bomem Michelson MB100 FTIR spectrophotometer with a resolution of 4 $\mathrm{cm}^{-1}$ in the absorbance mode. Water contact angle of the formulated TAN coating was measured using an optical equipment model OCA 15E (Dataphysics Instruments), equipped with a $500 \mu \mathrm{L}$ precision syringe (DS 500GTand the SCA 20 software for data processing. The contact angle was measured in six different areas of the sample, the average value being used to determine the surface wettability. 


\subsection{Immersion tests}

COM, TAN and blank samples were immersed in the Mediterranean Sea at Badalona Port $\left(41^{\circ} 26^{\prime} 08.4^{\prime \prime} \mathrm{N}, 2^{\circ} 14^{\prime} 33.0^{\prime \prime} \mathrm{E}\right)$ in Spain. The immersion tests were carried out between April and November of 2013, period of intense activity of some fouling organisms. ${ }^{46,47}$ Panels were fixed with nylon straps on a poly(vinyl chloride) support. The poly(vinyl chloride) support was built with tubes covered by polyurethane foam to avoid contact between samples and dock walls. The support was immersed in water to a depth of approximately $60 \mathrm{~cm}$ according to ASTM D $3623^{48}$ standard and Pérez et al. ${ }^{41}$ work. The panel aspect and degree of fouling attachment were verified every month. The fouling degree was evaluated according to fouling covering, where $100 \%$ means complete coverage of the panel by organisms and $0 \%$ means total absence. ${ }^{49}$ According to ASTM D3623 stipulations, the fouling covering at distances lower than $1.3 \mathrm{~cm}$ from the panels edges were not considered for the calculation of the fouling degree. ${ }^{48}$

\section{Results and Discussion}

\subsection{Mechanism of antifouling coating functioning}

As mentioned before, the antifouling activity of tannins was reported in the literature by some authors. ${ }^{6,34-43}$ In the mechanism of antifouling coating functioning, the bacteria repulsion, ${ }^{35}$ narcotic $^{38}$ and settlement-inhibitory ${ }^{36}$ effects of tannins were considered. Figure 1 shows a hypothetic mechanistic scheme of TAN functioning in marine environment. Initially, bacteria and fouling organisms approach to substrate finding a tannin-rich surface. The antifouling coating contains both tannin adsorbed into theactivated carbon pores and low soluble tannin fractions, which acts repulsing the bacteria, immobilizing the fouling larvae and inhibiting the fouling settlement. ${ }^{35,36,38}$ 
Simultaneously, the rosin matrix is launched to the water environment and a new antifouling layer rich in tannin appears. The formation of soluble resinates with $\mathrm{Na}^{+}$ and $\mathrm{K}^{+}$ions in water is responsible for the solubilisation of the rosin. ${ }^{50}$

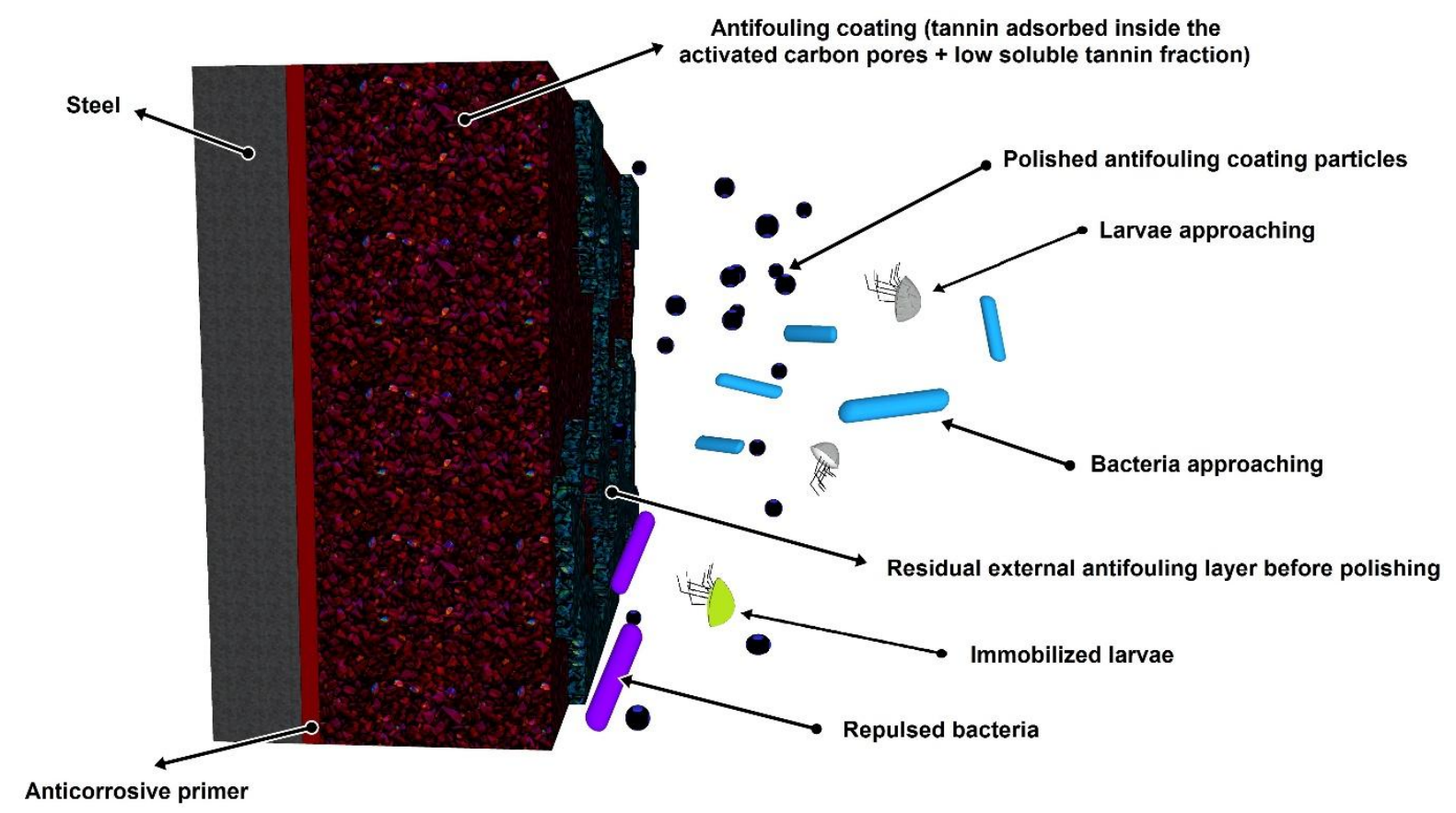

Figure 1: Hypothetical scheme of TAN coating action in marine environment.

\subsection{Black wattle tannin modification}

The complexity of tannins chemical forms require techniques as NMR to identify the many structures of these compounds. ${ }^{51}$ The ${ }^{13} \mathrm{C}$ NMR technique was used to identify the chemical structures of black wattle tannin before and after hydrolysis reaction.

The ${ }^{13} \mathrm{C}$ NMR spectrum of black wattle tannin in DMSO- $d_{6}$ is shown in Figure 2. The inset in Figure 2 represents a schematic structure of condensed tannin, where $R_{1}$ and $R_{2}$ can be $-\mathrm{OH}$ or $-\mathrm{H}$. If $\mathrm{R}_{1}=-\mathrm{OH}$ and $\mathrm{R}_{2}=-\mathrm{H}$ the chemical structure corresponds to procyanidin $^{52}$ while if $\mathrm{R}_{1}=\mathrm{R}_{2}=-\mathrm{OH}$, the chemical structure is prodelphindin. ${ }^{52}$ 


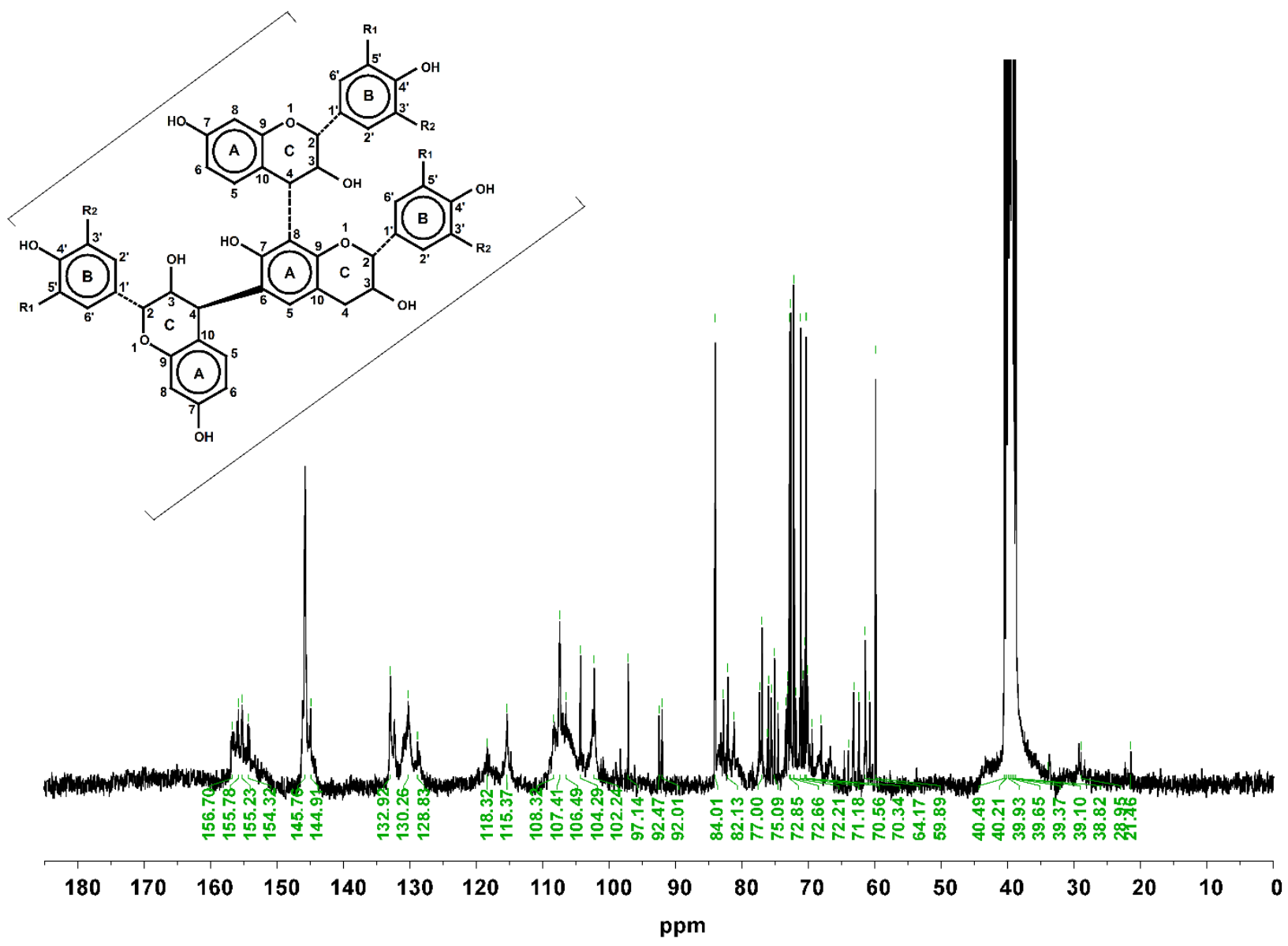

Figure 2: ${ }^{13} \mathrm{C}$ NMR spectrum of black wattle tannin in DMSO- $d_{6}$. The inset represents a schematic structure of condensed tannin. Procyanidin corresponds to $\mathrm{R}_{1}=-\mathrm{OH}$ and $\mathrm{R}_{2}=$ $-\mathrm{H}$, whereas prodelphindin refers to $\mathrm{R}_{1}=\mathrm{R}_{2}=-\mathrm{OH} .^{52}$

Chemical shifts reported for different polyphenols ${ }^{51-62}$ were used to identify the peaks obtained for black wattle tannin (Figure 2). The peak at $145 \mathrm{ppm}$ corresponds to the $\mathrm{C}^{\prime}{ }^{\prime}$ and $\mathrm{C}^{\prime}{ }^{\prime}$ of B-ring while and peaks at $156-154 \mathrm{ppm}$ are associated to the $\mathrm{C} 5$ and C7 (A-ring) bonded to $-\mathrm{OH} \cdot{ }^{57,58}$ The chemical shifts at 133 and 118 ppm belongs to the $\mathrm{C} 1^{\prime}$ and $\mathrm{C}^{\prime}$ atoms, respectively, of B-ring. ${ }^{57,58}$ The peak at $115 \mathrm{ppm}$ corresponds to the C4-C8 interflavonoid bond while those at 107-105 to the C4-C6 interflavonoid bond. $^{57,58}$ The peak at 97 ppm corresponds to the terminal C6, C8 and C10 of A-ring. The chemical shifts between 68 and 75 ppm are associated to the $\mathrm{C} 3$ atom and C4-C8 
and C4-C6 interflavonoid bonds. It should be mentioned that characteristic peaks of glycosides also appear in the latter region of the spectrum and, therefore, can overlapp the flavonoids peaks. ${ }^{51,52,55,60,62}$ The bands at 75-77 ppm are associated to $\mathrm{C} 2$ (C-ring) in cis position while those at $82 \mathrm{ppm}$ involve the trans form. ${ }^{51,53,62}$ The band at $64.17 \mathrm{ppm}$ corresponds to C3 while terminal C4 appears in $29-27$ ppm. $^{53,62}$

In spite of polymerized black wattle tannin is highly soluble in water, first attempts for its adsorption in the activated carbon were unsuccessful. Accordingly, hydrolysis of tannin was proposed to facilitate the adsorption step. The cleavage of interflavonoid bond by acid-catalysed reaction decreases the molecular weight of tannin leading to the formation of highly soluble (anthocyanidins) and poorly soluble products. ${ }^{21,45,63}$ The soluble products were successfully adsorbed in activated carbon and tested as antifouling pigment, together with the poorly soluble products. The ${ }^{13} \mathrm{C}$ NMR spectrum of black wattle tannin after hydrolysis reaction (soluble fraction diluted in DMSO- $d_{6}$ ) is given in Figure 3. The inset in Figure 3 represents a schematic structure of black wattle tannin after hydrolysis reaction, where $\mathrm{R}_{1}, \mathrm{R}_{2}$ and $\mathrm{R}_{3}$ can be $-\mathrm{OH}$ or $-\mathrm{H}$. As examples, if $\mathrm{R}_{1}=-\mathrm{OH}, \mathrm{R}_{2}=-\mathrm{OH}$ and $\mathrm{R}_{3}=-\mathrm{H}$ the chemical structure corresponds to catechin, whereas if $\mathrm{R}_{4}=\mathrm{R}_{2}=-\mathrm{OH}$ and $\mathrm{R}_{3}=-\mathrm{H}$, the chemical structure refers to epicatechin. 


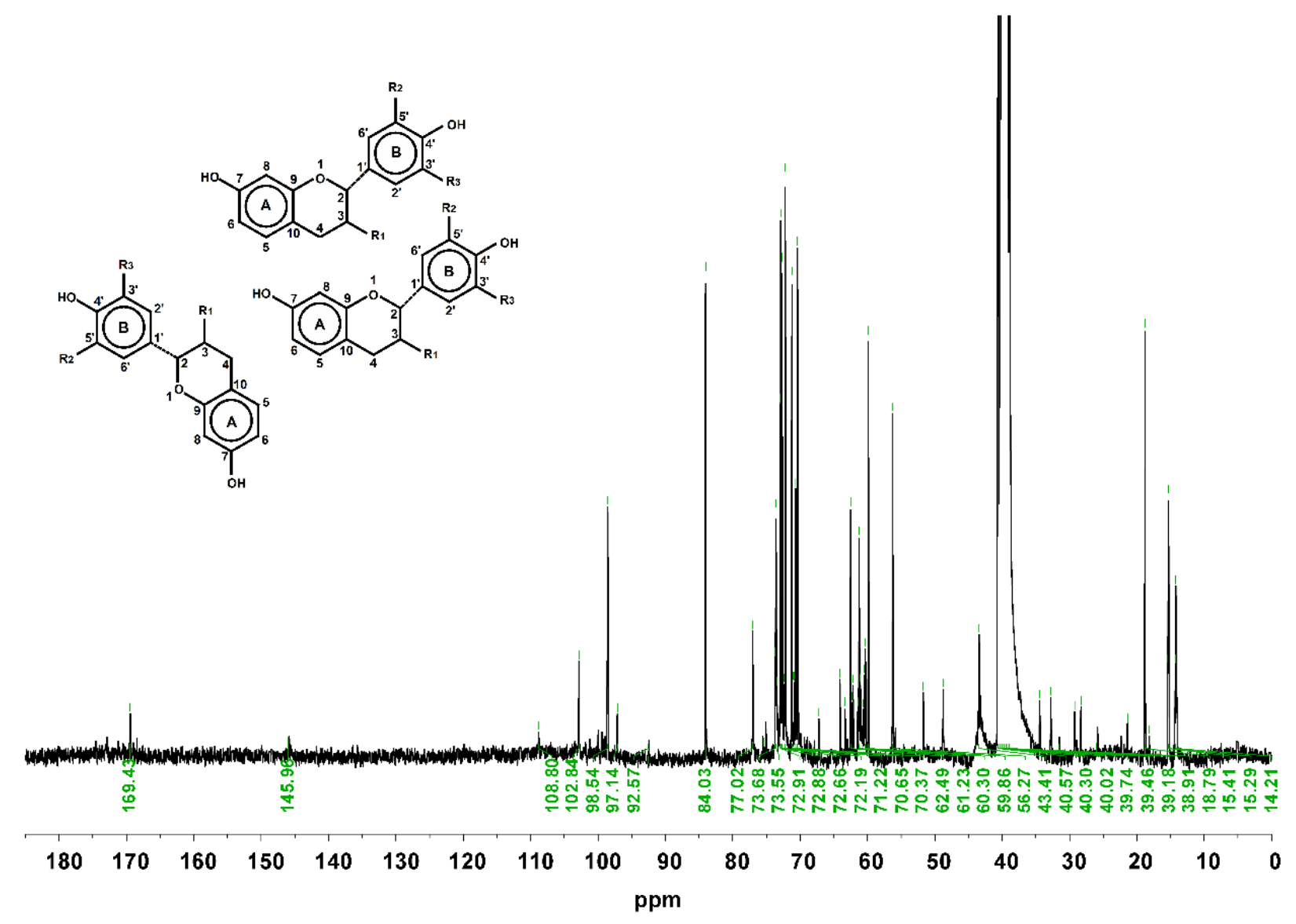

Figure 3: ${ }^{13} \mathrm{C}$ NMR spectrum of black wattle tannin in DMSO- $d_{6}$. The inset represents a schematic structure of condensed tannin. If $\mathrm{R}_{1}=\mathrm{R}_{2}=-\mathrm{OH}$ and $\mathrm{R}_{3}=-\mathrm{H}$ the chemical structure corresponds to catechin, whereas if $\mathrm{R}_{4}==$, $\mathrm{R}_{2}=-\mathrm{OH}$ and $\mathrm{R}_{3}=-\mathrm{H}$ the chemical structure refers to epicatechin. ${ }^{52}$

The characteristic chemical shifts of black wattle tannin after hydrolysis reaction (Figure 3) were identified according to the literature. ${ }^{51-62}$ Although many peaks are similar to the black wattle tannin spectrum, some changes are detected at signals associated to the interflavonoid bonds. The chemical shift at $115 \mathrm{ppm}$ (C4-C8 interflavonoid bond) and at 107-105 (C4-C6 interflavonoid bond) disappear in the spectrum of tannin after hydrolysis reaction. Some bands at $68-75 \mathrm{ppm}$ related to the C4-C8 and C4-C6 interflavonoid bonds disappear as well. Other important modifications was the appearance of a new chemical shift at $19 \mathrm{ppm}$, which correspond 
to the free $\mathrm{C} 4$ in the A-ring. ${ }^{57}$ A displacement in the 97 ppm peak, which corresponds to terminal $\mathrm{C} 6$ and $\mathrm{C} 8$, is also observed. These modifications in the spectrum corroborate the cleavage of interflavonoid bonds, as expected from the hydrolysis reaction. ${ }^{45,64,65}$

\subsection{Characterization of antifouling coating surface by FTIR}

Chemical modifications underwent at the TAN coating surface after 7 months of immersion at Badalona port (Mediterranean Sea) was verified by FTIR. The FTIR spectra of tannin, rosin, TAN and TAN after 7 months of immersion are displayed in Figure 4. The spectrum of pure rosin ( Figure 4a) shows the band of the $-\mathrm{CO}$ from diterpenic acids at $1690 \mathrm{~cm}^{-1}$ while peaks at $1386 \mathrm{~cm}^{-1}$ and $1445 \mathrm{~cm}^{-1}$ correspond to $\mathrm{CH}_{3}$ bending vibration. ${ }^{66}$ Peaks at $1238 \mathrm{~cm}^{-1}$ and $963 \mathrm{~cm}^{-1}$ refer to $-\mathrm{COOH}$. The peaks at $1613,887,830 \mathrm{~cm}^{-1}$ and $706 \mathrm{~cm}^{-1}$ are assigned to aromatic groups while the peak at $1183 \mathrm{~cm}^{-1}$ is attributed to saturated $\mathrm{C}-\mathrm{C}$ or $-\mathrm{CH}$ in an aromatic ring. ${ }^{67}$

As expected, the peaks at the FTIR spectrum of TAN before immersion (Figure 4b) are similar to the rosin resin due to entrapment of pigments inside the rosin matrix. However, after 7 months of immersion (Figure 4c) the peaks of TAN coating show important differences. The bands at 1547,1390 and $1145 \mathrm{~cm}^{-1}$, which correspond to $\mathrm{C}=\mathrm{C}$ of aromatic groups, ${ }^{68} \mathrm{COH}$ deformation of phenols ${ }^{69}$ and aromatic $\vee \mathrm{C}-\mathrm{O},{ }^{70}$ respectively, appear in TAN (after immersion) and black wattle tannin (inset of Figure 4) spectra. These bands are related to polyphenolic compounds, confirming that part of the rosin matrix was launched to water and the tannin was exposed. Other important result of FTIR analysis corresponds to the presence of tannin in the TAN coating, even after 7 months of immersion. 


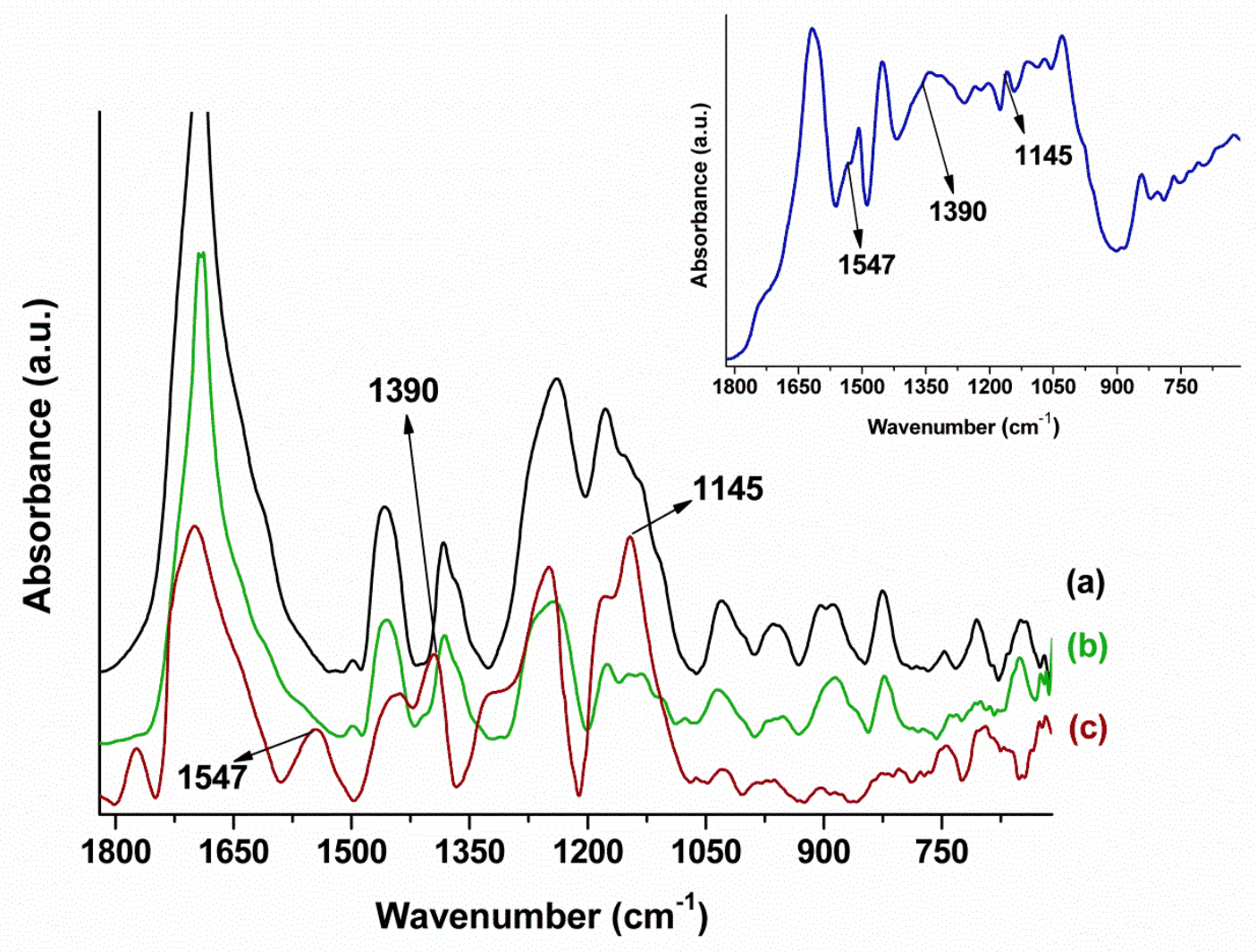

Figure 4: FTIR spectra of (a) rosin, (b) TAN coating before immersion and (c) TAN coating after 7 months of immersion at Badalona port (Mediterranean Sea). The inset shows the FTIR spectrum of black wattle tannin.

\subsection{Water contact angle of antifouling coating surface}

In order to get more information about the behaviour of the TAN coating surface in marine environment, water contact measurements were carried out. The mean contact angle measured for TAN was $72.9^{\circ} \pm 0.7^{\circ}$ (Figure 5) indicating good surface wettability. ${ }^{71}$ This low angle value favours the action of the TAN coating since water is enabled to penetrate inside the pores of activated carbon. Hydrophilicity is also important for the solubilisation of low soluble tannin fraction. 


\section{$\square$}

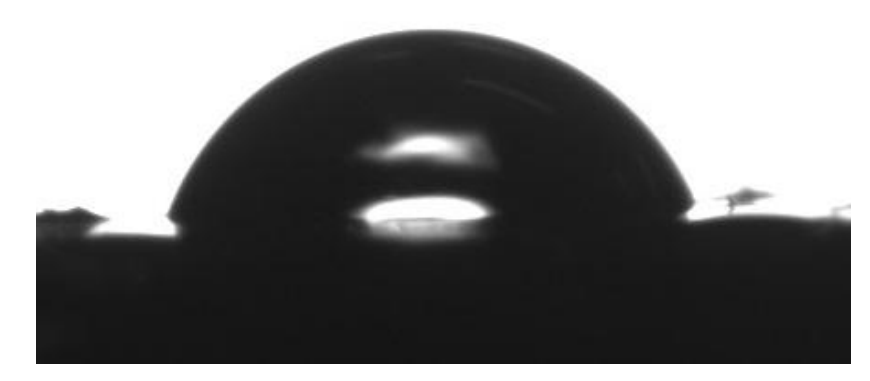

Figure 5: Water droplet representation of TAN coating.

\subsection{Immersion tests}

Painted panels were immersed in Badalona port (Mediterranean Sea) to verify the antifouling efficiency of TAN coating. Together with TAN samples, panels painted with anticorrosive primer (blank) and commercial antifouling coating (COM) were immersed at the same place and time.

Figure 6 shows the aspect of tested panels before and after 2, 4 and 7 months of immersion. The blank panel (Figure 6b) show many points of fouling attachment after only two months of immersion while both the COM (Figure 6j) and TAN (Figure 6f) coatings remain without fouling after such period of time. In the fourth month, the area covered by fouling of the blank (Figure 6c) increased significantly, while no hard or soft fouling was attached to the TAN (Figure 6g) and COM (Figure 6k) coatings. Callow et $a l .^{3}$ classified the fouling degree as hard and soft depending on the attached fouling organisms.

The COM coating (Figure 61) remained without attached fouling during the whole immersion assay ( 7 months), even though many failures, as bubbles and detached 
areas, were found in the coating. On the contrary, the blank panel (Figure 6d) was completely covered by fouling after 7 months of immersion,. In the TAN coating (Figure 6h), only soft fouling (some algae and hydroids) was detected in a few points of the surface. Indeed, detailed inspection reveals that this phenomenon is exclusively localized at some failure surface regions (detached areas).. These observations clearly reflect the excellent antifouling properties of the TAN coating.
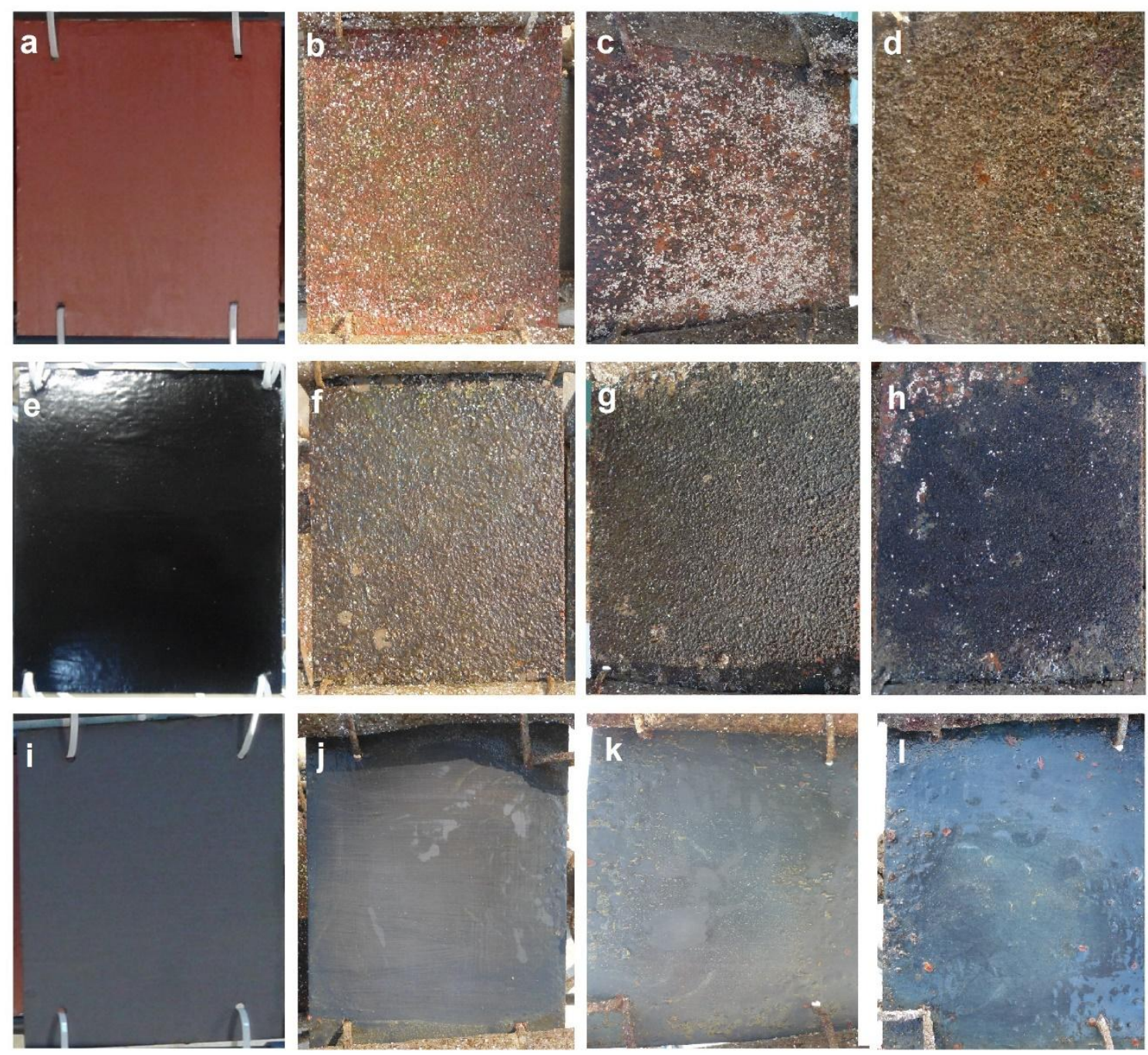

Figure 6: Photographs of (a) blank, (e) TAN and (i) COM samples before immersion at Badalona port (Mediterranean Sea); (b) blank, (f) TAN and (j) COM after 2 months; (c) blank, (g) TAN and (k) COM samples after 4 months; and (d) blank, (h) TAN and (l) 
COM samples after 7 months. The dimension of each steel panel is $25 \mathrm{~cm} \times 20 \mathrm{~cm} \times 1$ $\mathrm{mm}^{3}$.

\subsection{Microscopy analysis}

In order to analyse the surface of TAN coating after seven months of immersion, analyses based on SEM and optical microscopies were carried out. Figure 7 shows optical micrographs of the surface of blank panels. As can be seen, hard fouling is present on the entire surface (Figure 7a). Thus, tubeworms, barnacle, sponges and mussels are detected (Figure 7c). The thickness of fouling layer on the blank panel reaches $7 \mathrm{~mm}$ in some areas, as is evidenced in Figure $7 \mathrm{e}$.

Figure $7 \mathrm{~b}$ displays the optical micrograph of COM surface, while Figures $7 \mathrm{~d}$ and 7f shows optical micrographs of TAN surface. The cracks and detached parts of TAN and COM surfaces appear after drying. . The latter refers to the elimination of moisture at dry environmental conditions from wet samples after 7 months of exposure in water environment and not the drying step after painting. However, the COM sample already showed some detached parts before such drying step (Figure 71 ). Figure $7 b$ reflects the absence of fouling in the COM surface. Figure $7 \mathrm{~d}$ reveals the presence of light fouling (algae) at some points of the TAN surface, as observed in the photograph displayed in Figure 6h. However, hard fouling is absent, as is clearly evidenced by comparing the two sides of the panel (Figure 7f). Thus, the thickness of the side painted with TAN coating (right side in Figure 7f) is considerably smaller than that of back side (left in Figure 7f), which was not painted with antifouling coating and presents significant amounts of hard fouling. 

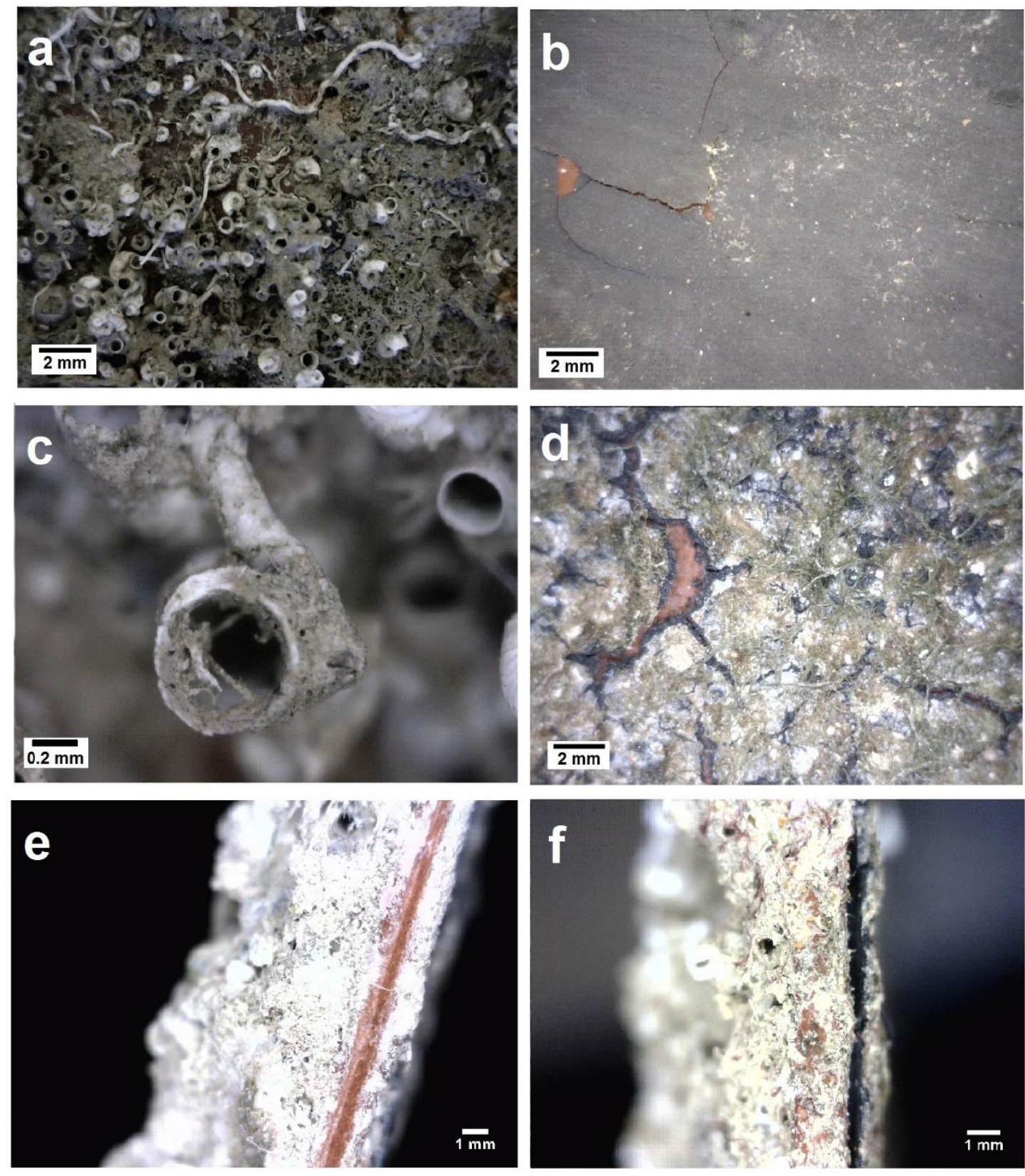

Figure 7: Optical Micrographs of blank (a, c and e), TAN (d and f) and COM (b) samples after immersion tests.

SEM micrographs of TAN coating surface after 7 months of immersion are displayed in Figure 8. As observed in the optical image (Figure 7d), there is only soft 
fouling in some points on the TAN surface. Figure 8a shows the TAN sample with some algae branches on the surface. At high magnification, the presence of unicellular algae called diatoms is detected (Figure $8 \mathrm{~b}$ ). According to Callow et al. ${ }^{3}$, diatoms are species of Amphora able to grow on some copper antifouling coatings surface. Diatoms can form a slime (biofilm) whose average thickness can reach values as high as 500 $\mu \mathrm{m} .{ }^{3}$ The antifouling efficiency of TAN coating is reaffirmed by SEM analysis, because only soft fouling is detected, as occurs in the copper antifouling coatings. In the areas with no algae, the high porosity of TAN coating is verified (Figures $8 \mathrm{c}$ and $8 \mathrm{~d}$ ). These porous are important for the proper releasing of black wattle tannin.
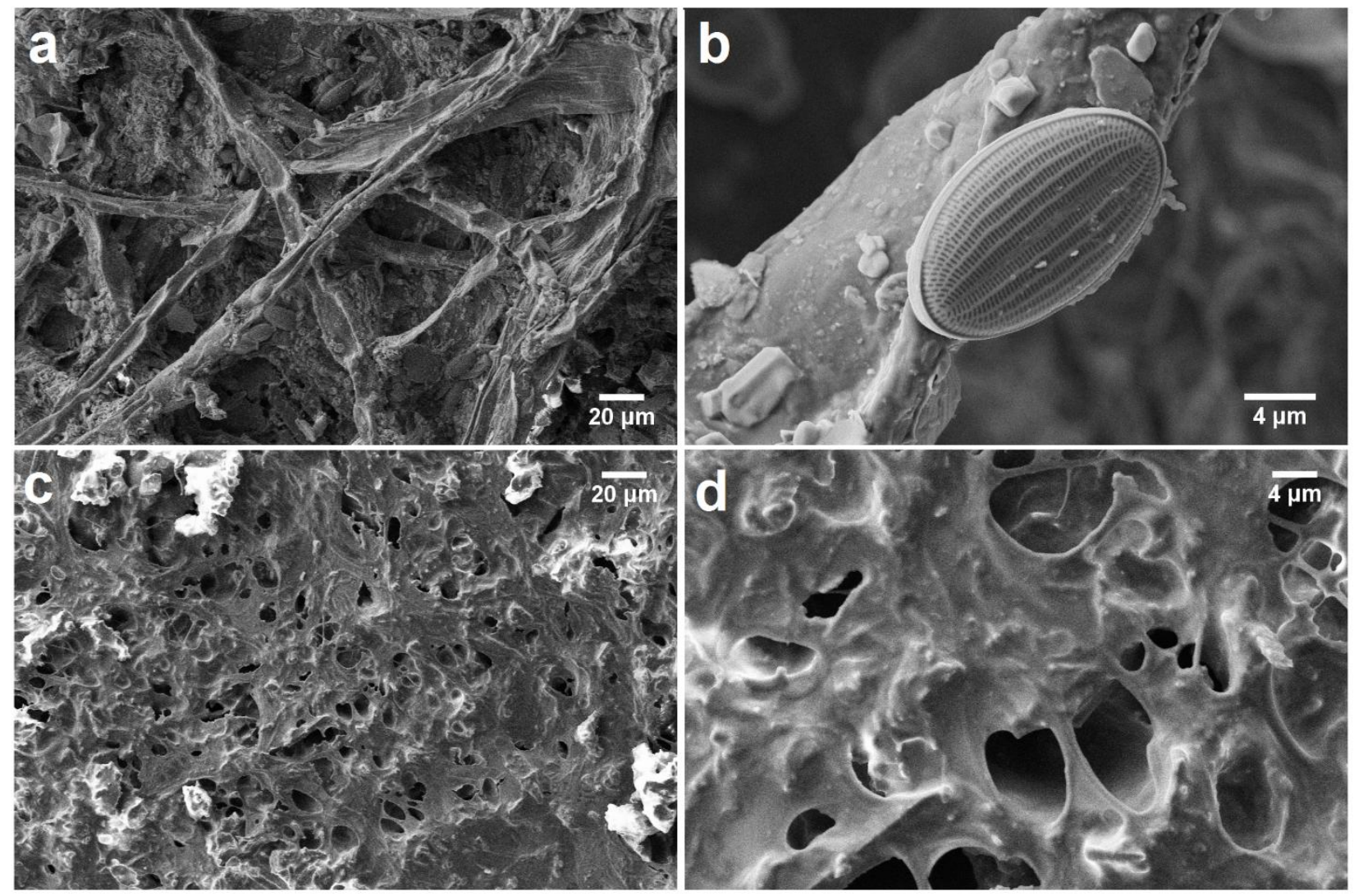

Figure 8: SEM micrographs of TAN antifouling coating: (a) area covered by soft fouling (algae); (b) diatoms on the TAN surface; (c) and (d) porosity of TAN coatings at different magnifications. 


\section{Conclusions}

The antifouling activity of a tannin-based antifouling coating (TAN) was proved in this work. The modification of black wattle tannin through the cleavage of tannin interflavonoid bonds has been confirmed by ${ }^{13} \mathrm{C}$ NMR spectroscopy. Furthermore, the presence of tannin in the formulated antifouling coating, even after 7 months of its exposure in marine environment, has been evidenced by FTIR spectroscopy. Water contact angle analysis has shown the hydrophilic nature of the tannin antifouling coating surface.

Immersion tests at Badalona port in Mediterranean Sea have reflected the high antifouling efficiency of TAN coating until 7 months, being comparable to that of the commercial paint. Photographs and optical images of blank samples have evidenced the high activity of fouling organisms in the tested area. Microscopy analyses together with photographs of immersed samples have confirmed the presence of only soft fouling on the TAN surface. As final remark, results obtained in this work indicate that the use of natural black wattle tannin, without complexation with metals, can eliminate the release of metals and other toxic species to the marine environment. Thus, the negative impact in the environment can be drastically reduced or even eliminated with the use of tannins as antifouling agents.

\section{Acknowledgments}

The authors thank the Brazilian government agencies CNPq and CAPES (process BEX 13736124) which provided the financial support for this study and the scholarship for R.S Peres. Financial support for E.A. and C.A. comes from MICINN and FEDER (MAT2012-34498), and the Generalitat de Catalunya (research group 2009 SGR 925) is 
gratefully acknowledged. Support for the research of C.A. was received through the "ICREA Academia" prize for excellence in research funded by the Generalitat de Catalunya.

\section{References}

(1) Redfield, A. C.; Hutchins, L. W. In Marine Fouling and its Prevention; Redfield, A. C., Ketchum, B. H., Eds.; George Banta Publishing Co.: Menasha, 1952.

(2) Wahl, M., Marine epibiosis. I. Fouling and antifouling: some basic aspects, Marine Ecology Progress Series 1989, 58, 175-189.

(3) Callow, M. E.; Callow, J. A., Marine biofouling: a sticky problem, Biologist 2002, $49,1-5$.

(4) Senda, T. In Ecotoxicology of Antifouling Biocides; Arai, T., Harino, H., Eds.; Springer Tokyo, 2009; pp 23-38.

(5) Lewandowski, Z.; Beyenal, H. In Marine and Industrial Biofouling; Flemming, H.-C., Murthy, P. S., Venkatesan, R., Cooksey, K., Costerton, J. W., Eds.; Springer: Berlin, 2009; pp 35-64.

(6) Pérez, M.; Blustein, G.; García, M.; del Amo, B.; Stupak, M., Cupric tannate: A low copper content antifouling pigment, Progress in Organic Coatings 2006, 55, 311-315.

(7) Readman, J. W. In Antifouling Paint Biocides; Konstantinou, I. K., Ed.; Springer: Berlin, 2006; pp 1-16.

(8) Goldberg, E. D., TBT: An Environmental Dilemma, Environment: Science and Policy for Sustainable Development 1986, 28, 17-44.

(9) His, E.; Robert, R., Developpement des veligeres de Crassostrea gigas dans le bassin d'Arcachon. Etudes sur les mortalites larvaires, Revue des Travaux de I'Institut des Pêches Maritimes 1983, 47, 63-88.

(10) Alzieu, C., Environmental impact of TBT: the French experience, Science of The Total Environment 2000, 258, 99-102.

(11) IMO, 2001.

(12) Flemming, C.; Trevors, J., Copper toxicity and chemistry in the environment: a review, Water, Air, and Soil Pollution 1989, 44, 143-158.

(13) Devilla, R. A.; Brown, M. T.; Donkin, M.; Readman, J. W., The effects of a PSII inhibitor on phytoplankton community structure as assessed by HPLC pigment analyses, microscopy and flow cytometry, Aquatic toxicology 2005, 71, 25-38.

(14) Chesworth, J.; Donkin, M.; Brown, M., The interactive effects of the antifouling herbicides Irgarol 1051 and Diuron on the seagrass< i> Zostera marina</i>(L.), Aquatic toxicology 2004, 66, 293-305.

(15) Arai, T.; Harino, H.; Ohji, M.; Langston, W. J. Ecotoxicology of antifouling biocides; Springer, 2009; Vol. 14.

(16) Etoh, H.; Kondoh, T.; Noda, R.; Singh, I. P.; Sekiwa, Y.; Morimitsu, K.; Kubota, K., Shogaols from Zingiber officinale as promising antifouling agents, Bioscience Biotechnology and Biochemistry 2002, 66, 1748-1763.

(17) Etoh, H.; Kondoh, T.; Yoshioka, N.; Sugiyama, K.; Ishikawa, H.; Tanaka, H., 9Oxo-neoprocurcumenol from Curcuma aromatica (Zingiberaceae) as an attachment inhibitor 
against the blue mussel, Mytilus edulis galloprovincialis, Bioscience, biotechnology, and biochemistry 2003, 67, 911-913.

(18) Watts, J. L., 1995; Vol. US5397385 A.

(19) Qian, P.-Y.; Xu, Y.; Fusetani, N., Natural products as antifouling compounds: recent progress and future perspectives, Biofouling 2010, 26, 223-234.

(20) Hagerman, A.; Robbins, C., Implications of soluble tannin-protein complexes for tannin analysis and plant defense mechanisms, J Chem Ecol 1987, 13, 1243-1259.

(21) Hillis, W. E. In Black Wattle and its Utilisation; first ed.; Brown, A. G., Ko, H. C., Eds.; Rural Industries Research and Development Corporation: Barton, 1997; pp 106-121.

(22) Rahim, A. A.; Kassim, J., Recent development of vegetal tannins in corrosion protection of iron and steel, Recent Patents on Materials Science 2008, 1, 223-231.

(23) Amarowicz, R., Tannins: the new natural antioxidants?, European Journal of Lipid Science and Technology 2007, 109, 549-551.

(24) Bate-Smith, E.; Swain, T., Flavonoid compounds, Comparative biochemistry $1962,3,705-809$.

(25) Hagerman Ann, E.; Zhao, Y.; Johnson, S. In Antinutrients and Phytochemicals in Food; American Chemical Society, 1997; Vol. 662; pp 209-222.

(26) Hernes, P. J.; Benner, R.; Cowie, G. L.; Goñi, M. A.; Bergamaschi, B. A.; Hedges, J. I., Tannin diagenesis in mangrove leaves from a tropical estuary: a novel molecular approach, Geochimica et Cosmochimica Acta 2001, 65, 3109-3122.

(27) Peres, R. S.; Cassel, E.; Ferreira, C. A.; Azambuja, D. S., Grain Refiner Effect of Black Wattle Tannin in Iron and Zinc Phosphate Coatings, Industrial \& Engineering Chemistry Research 2014, 53, 2706-2712.

(28) Peres, R. S.; Cassel, E.; Ferreira, C. A.; Azambuja, D. S., Black wattle tannin as a zinc phosphating coating sealer, Surface and Interface Analysis 2014, 46, 1-6.

(29) Rahim, A. A.; Rocca, E.; Steinmetz, J.; Jain Kassim, M., Inhibitive action of mangrove tannins and phosphoric acid on pre-rusted steel via electrochemical methods, Corrosion Science 2008, 50, 1546-1550.

(30) Rahim, A. A.; Rocca, E.; Steinmetz, J.; Kassim, M.; Adnan, R.; Sani Ibrahim, M., Mangrove tannins and their flavanoid monomers as alternative steel corrosion inhibitors in acidic medium, Corrosion Science 2007, 49, 402-417.

(31) Matamala, G.; Smeltzer, W.; Droguett, G., Comparison of steel anticorrosive protection formulated with natural tannins extracted from acacia and from pine bark, Corrosion Science 2000, 42, 1351-1362.

(32) Simon, C.; Pizzi, A., Tannins/melamine-urea-formaldehyde (MUF) resins substitution of chrome in leather and its characterization by thermomechanical analysis, Journal of applied polymer science 2003, 88, 1889-1903.

(33) Pizzi, A., Condensed tannins for adhesives, Industrial \& Engineering Chemistry Product Research and Development 1982, 21, 359-369.

(34) Sieburth, J. M.; Conover, J. T., Sargassum tannin, an antibiotic which retards fouling, Nature 1965, 208, 52-53.

(35) Chet, I.; Asketh, P.; Mitchell, R., Repulsion of bacteria from marine surfaces, Applied microbiology 1975, 30, 1043-1045.

(36) Lau, S. C. K.; Qian, P. Y., Inhibitory effect of phenolic compounds and marine bacteria on larval settlement of the barnacle Balanus amphitrite amphitrite darwin, Biofouling 2000, 16, 47-58.

(37) Pérez, M.; Garcia, M.; Blustein, G.; Stupak, M., Tannin and tannate from the quebracho tree: an eco-friendly alternative for controlling marine biofouling, Biofouling 2007, 23, 151-159.

, M. T.; Pérez, M. C., Non-toxic alternative compounds for marine antifouling paints, International biodeterioration \& biodegradation 2003, 52, 49-52. 
(39) Bellotti, N.; del Amo, B.; Romagnoli, R., Tara tannin a natural product with antifouling coating application, Progress in Organic Coatings 2012, 74, 411-417.

(40) Bellotti, N.; Deyá, C.; del Amo, B.; Romagnoli, R., "Quebracho" tannin derivative and boosters biocides for new antifouling formulations, Journal of Coatings Technology and Research 2012, 9, 551-559.

, C.; del Amo, B.; Romagnoli, R., Antifouling Paints with Zinc "Tannate", Industrial \& Engineering Chemistry Research 2010, 49, 3386-3390.

(42) Bellotti, N.; del Amo, B.; Romagnoli, R., Caesalpinia spinosa tannin derivatives for antifouling formulations, Procedia Materials Science 2012, 1, 259-265.

(43) Bellotti, N.; del Amo, B.; Romagnoli, R., Quaternary Ammonium "Tannate" for Antifouling Coatings, Industrial \& Engineering Chemistry Research 2012, 51, 16626-16632.

(44) Slabbert, N. In Plant Polyphenols; Hemingway, R., Laks, P., Eds.; Springer US, 1992; Vol. 59; pp 421-436.

(45) Swain, T.; Hillis, W., The phenolic constituents of Prunus domestica. I. -The quantitative analysis of phenolic constituents, Journal of the Science of Food and Agriculture 1959, 10, 63-68.

(46) Anil; C., A.; Chiba; K.; Okamoto; Kurokura; H., Influence of temperature and salinity on larval development of Balanus amphitrite: implications in fouling ecology, Marine Ecology Progress Series 1995, 118, 159-166.

(47) Chiu, J. M. Y.; Thiyagarajan, V.; Tsoi, M. M. Y.; Qian, P. Y., Qualitative and quantitative changes in marine biofilms as a function of temperature and salinity in summer and winter, Biofilms 2005, 2, 183-195.

(48) ASTM D3623 - 78a: Standard Test Method for Testing Antifouling Panels in Shallow Submergence, 2004.

(49) 2011.

(50) Yebra, D. M.; Kiil, S.; Dam-Johansen, K.; Weinell, C., Reaction rate estimation of controlled-release antifouling paint binders: Rosin-based systems, Progress in Organic Coatings 2005, 53, 256-275.

(51) Ucar, M. B.; Ucar, G.; Pizzi, A.; Gonultas, O., Characterization of Pinus brutia bark tannin by MALDI-TOF MS and 13C NMR, Industrial Crops and Products 2013, 49, 697-704.

(52) Chai, W.-M.; Shi, Y.; Feng, H.-L.; Qiu, L.; Zhou, H.-C.; Deng, Z.-W.; Yan, C.-L.; Chen, Q.-X., NMR, HPLC-ESI-MS, and MALDI-TOF MS Analysis of Condensed Tannins from Delonix regia (Bojer ex Hook.) Raf. and Their Bioactivities, Journal of Agricultural and Food Chemistry 2012, 60, 5013-5022.

(53) Czochanska, Z.; Foo, L. Y.; Newman, R. H.; Porter, L. J., Polymeric proanthocyanidins. Stereochemistry, structural units, and molecular weight, Journal of the Chemical Society, Perkin Transactions 1 1980, 2278-2286.

(54) Cren-Olivé, C.; Wieruszeski, J.-M.; Maes, E.; Rolando, C., Catechin and epicatechin deprotonation followed by $13 C$ NMR, Tetrahedron Letters 2002, 43, 4545-4549.

(55) Castillo-Muñoz, N.; Gómez-Alonso, S.; García-Romero, E.; Gómez, M. V.; Velders, A. H.; Hermosín-Gutiérrez, I., Flavonol 3-O-Glycosides Series of Vitis vinifera Cv. Petit Verdot Red Wine Grapes, Journal of Agricultural and Food Chemistry 2008, 57, 209-219.

(56) Wawer, I.; Wolniak, M.; Paradowska, K., Solid state NMR study of dietary fiber powders from aronia, bilberry, black currant and apple, Solid State Nuclear Magnetic Resonance 2006, 30, 106-113.

(57) Zhao, Y.; Yan, N.; Feng, M. W., Biobased Phenol Formaldehyde Resins Derived from Beetle-Infested Pine Barks-Structure and Composition, ACS Sustainable Chemistry \& Engineering 2012, 1, 91-101.

(58) Navarrete, P.; Pizzi, A.; Pasch, H.; Rode, K.; Delmotte, L., MALDI-TOF and $13 \mathrm{C}$ NMR characterization of maritime pine industrial tannin extract, Industrial Crops and Products 2010, 32, 105-110. 
(59) Davis, A. L.; Cai, Y.; Davies, A. P.; Lewis, J. R., $1 H$ and 13C NMR Assignments of Some Green Tea Polyphenols, Magnetic Resonance in Chemistry 1996, 34, 887-890.

(60) Watanabe, M., Catechins as Antioxidants from Buckwheat (Fagopyrum esculentum Moench) Groats, Journal of Agricultural and Food Chemistry 1998, 46, 839-845.

(61) Schmidt, B. M.; Howell, A. B.; McEniry, B.; Knight, C. T.; Seigler, D.; Erdman, J. W.; Lila, M. A., Effective Separation of Potent Antiproliferation and Antiadhesion Components from Wild Blueberry (Vaccinium angustifolium Ait.) Fruits, Journal of Agricultural and Food Chemistry 2004, 52, 6433-6442.

(62) Zhang, L.-L.; Lin, Y.-M.; Zhou, H.-C.; Wei, S.-D.; Chen, J.-H., Condensed Tannins from Mangrove Species Kandelia candel and Rhizophora mangle and Their Antioxidant Activity, Molecules 2010, 15, 420-431.

(63) Porter, L. J.; Hrstich, L. N.; Chan, B. G., The conversion of procyanidins and prodelphinidins to cyanidin and delphinidin, Phytochemistry 1985, 25, 223-230.

(64) Kennedy, J. A.; Jones, G. P., Analysis of Proanthocyanidin Cleavage Products Following Acid-Catalysis in the Presence of Excess Phloroglucinol, Journal of Agricultural and Food Chemistry 2001, 49, 1740-1746.

(65) Hemingway, R. W.; McGraw, G. W., Kinetics of Acid-Catalyzed Cleavage of Procyanidins, Journal of Wood Chemistry and Technology 1983, 3, 421-435.

(66) Azémard, C.; Vieillescazes, C.; Ménager, M., Effect of photodegradation on the identification of natural varnishes by FT-IR spectroscopy, Microchemical Journal 2014, 112, 137-149.

(67) Font, J.; Salvadó, N.; Butí, S.; Enrich, J., Fourier transform infrared spectroscopy as a suitable technique in the study of the materials used in waterproofing of archaeological amphorae, Analytica Chimica Acta 2007, 598, 119-127.

(68) Hussein, M. Z. b.; Ghotbi, M. Y.; Yahaya, A. H.; Abd Rahman, M. Z., Synthesis and characterization of (zinc-layered-gallate) nanohybrid using structural memory effect, Materials Chemistry and Physics 2009, 113, 491-496.

(69) Jensen, J. S.; Egebo, M.; Meyer, A. S., Identification of spectral regions for the quantification of red wine tannins with Fourier transform mid-infrared spectroscopy, Journal of Agricultural and Food Chemistry 2008, 56, 3493-3499.

(70) Soto, R.; Freer, J.; Baeza, J., Evidence of chemical reactions between di- and poly-glycidyl ether resins and tannins isolated from Pinus radiata D. Don bark, Bioresource Technology 2005, 96, 95-101.

(71) Yuan, Y.; Lee, T. R. In Surface Science Techniques; Bracco, G., Holst, B., Eds.; Springer Berlin Heidelberg, 2013; Vol. 51; pp 3-34. 